\title{
Peptide Inhibitors of the -Cobratoxin-Nicotinic Acetylcholine Receptor Interaction
}

Lynagh, Timothy; Kiontke, Stephan; Meyhoff-Madsen, Maria; Gless, Bengt H; Johannesen, Jónas; Kattelmann, Sabrina; Christiansen, Anders; Dufva, Martin; Laustsen, Andreas H.; Devkota, Kanchan Total number of authors:

14

Published in:

Journal of Medicinal Chemistry

Link to article, DOI:

10.1021/acs.jmedchem.0c01202

Publication date:

2020

Document Version

Publisher's PDF, also known as Version of record

Link back to DTU Orbit

Citation (APA):

Lynagh, T., Kiontke, S., Meyhoff-Madsen, M., Gless, B. H., Johannesen, J., Kattelmann, S., Christiansen, A., Dufva, M., Laustsen, A. H., Devkota, K., Olsen, C. A., Kümmel, D., Pless, S. A., \& Lohse, B. (2020). Peptide Inhibitors of the -Cobratoxin-Nicotinic Acetylcholine Receptor Interaction. Journal of Medicinal Chemistry, 63, 1370913718. https://doi.org/10.1021/acs.jmedchem.0c01202

\section{General rights}

Copyright and moral rights for the publications made accessible in the public portal are retained by the authors and/or other copyright owners and it is a condition of accessing publications that users recognise and abide by the legal requirements associated with these rights.

- Users may download and print one copy of any publication from the public portal for the purpose of private study or research.

- You may not further distribute the material or use it for any profit-making activity or commercial gain

- You may freely distribute the URL identifying the publication in the public portal 


\section{lamentat \\ Medicinal \\ Chemistry}

\section{Peptide Inhibitors of the $\alpha$-Cobratoxin-Nicotinic Acetylcholine Receptor Interaction}

Timothy Lynagh,* Stephan Kiontke, Maria Meyhoff-Madsen, Bengt H. Gless, Jónas Johannesen, Sabrina Kattelmann, Anders Christiansen, Martin Dufva, Andreas H. Laustsen, Kanchan Devkota, Christian A. Olsen, Daniel Kümmel, Stephan Alexander Pless, and Brian Lohse*

Cite This: J. Med. Chem. 2020, 63, 13709-13718

Read Online

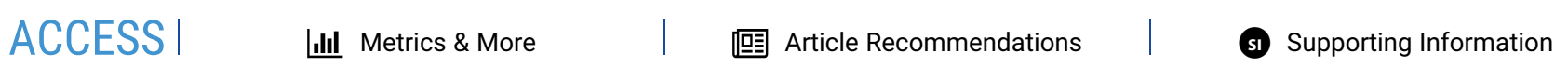

ABSTRACT: Venomous snakebites cause $>100000$ deaths every year, in many cases via potent depression of human neuromuscular signaling by snake $\alpha$-neurotoxins. Emergency therapy still relies on antibody-based antivenom, hampered by poor access, frequent adverse reactions, and cumbersome production/purification. Combining high-throughput discovery and subsequent structure-function characterization, we present simple peptides that bind $\alpha$-cobratoxin $(\alpha$-Cbtx $)$ and prevent its inhibition of nicotinic acetylcholine receptors (nAChRs) as a lead for the development of alternative antivenoms. Candidate peptides were identified by phage display and deep sequencing, and hits were characterized by electro-

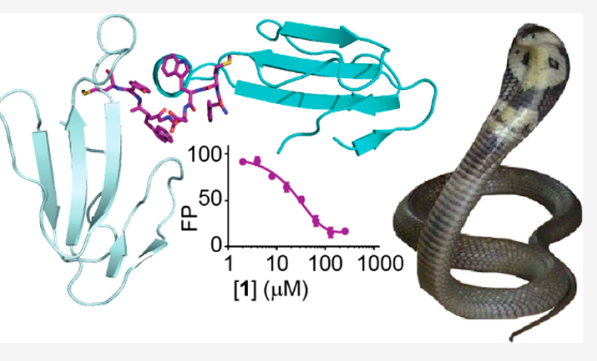
physiological recordings, leading to an 8-mer peptide that prevented $\alpha$-Cbtx inhibition of nAChRs. We also solved the peptide: $\alpha$-Cbtx cocrystal structure, revealing that the peptide, although of unique primary sequence, binds to $\alpha$-Cbtx by mimicking structural features of the nAChR binding pocket. This demonstrates the potential of small peptides to neutralize lethal snake toxins in vitro, establishing a potential route to simple, synthetic, low-cost antivenoms.

\section{INTRODUCTION}

Snakebite envenoming kills or maims hundreds of thousands of people every year, ${ }^{1,2}$ and loss of livestock is also emerging as a substantial problem. ${ }^{3}$ Treatment requires rapid transport to a medical facility and intravenous administration of antivenom, a mix of immunoglobulin $\mathrm{G}$ antibodies isolated from, e.g., horse or sheep immunized with snake venom. ${ }^{1}$ As the only effective treatment, antivenoms save numerous lives but have the disadvantages of time-consuming and expensive production, poor access for those in need, and alarming numbers of adverse reactions. $^{4-6}$ There is therefore an urgent need for novel treatments and new strategies, reflected in growing attention from the World Health Organization. ${ }^{7,8}$

In the case of elapid snakes, such as cobras and kraits, threefinger $\alpha$-neurotoxins such as $\alpha$-cobratoxin $(\alpha$-Cbtx) and $\alpha$ bungarotoxin $(\alpha$-Bgtx $)$ are the most prominent and lethal venom components. ${ }^{9-11} \alpha$-Cbtx and $\alpha$-Bgtx potently inhibit postsynaptic nicotinic acetylcholine receptors (nAChRs), which depresses neuromuscular signaling, causing paralysis and loss of respiration. ${ }^{12}$ The effectiveness of conventional antivenoms is limited by immunogenicity, abundance of $\alpha$-neurotoxin antibodies in the immunized animal at the time of production, ${ }^{13}$ and which type of snake inflicts the bite. Newer antibody-based strategies have emerged, with a focus on smaller, less immunogenic, and venom-specific antivenoms. Smaller camelid antibody fragments raised against cobra venom were shown to neutralize the effects of $\alpha$-Cbtx in mice and may allow for greater tissue penetration than conventional antivenoms. ${ }^{14}$ Phage display of a library of human-derived antibody single-chain variable fragments against $\alpha$-Bgtx from krait venom led to one fragment that neutralized toxin injected into mice. ${ }^{15}$ In the future, combinations of such lead entities could enable development of safe and effective treatments, as reflected in the recent application of cocktails of human monoclonal antibodies targeting mamba toxins. ${ }^{16}$ These showed promising neutralization of dendrotoxins in mice, although some improvement is needed in neutralizing $\alpha$-neurotoxins.

As an alternative to antibody-based strategies, we sought to discover short peptide-based neutralizers of $\alpha$-Cbtx by screening phage display peptide libraries for $\alpha$-Cbtx binders. Hits were then tested for neutralization of $\alpha$-Cbtx inhibition of nicotinic $\mathrm{nAChRs}$ using electrophysiology. This led to the identification of an effective 8-mer peptide, for which we solved the peptide: $\alpha$ Cbtx X-ray cocrystal structure, revealing the detailed binding mode. The identification and characterization of short peptide neutralizers of $\alpha$-Cbtx could lead to the development of targeted, fully synthetic, next-generation antivenoms for snakebite envenoming.

Received: July 21, 2020

Published: November 4, 2020 
Table 1. Phage Display Hits, Derivatives Thereof, and Their Prevention of $\alpha$-Cbtx Inhibition of nAChRs

\begin{tabular}{|c|c|c|c|c|}
\hline peptide & sequence & fold prevention of $\alpha$-Cbtx inhibition ${ }^{a}$ & affinity $^{b}$ & identified by \\
\hline & no peptide ( $\alpha$-cbtx alone) & 1.0 & & \\
\hline 1 & Ac-HAKTYMWDGWYMPTSH- $\mathrm{NH}_{2}$ & 7.4 & $2 \pm 2 \mu \mathrm{M}$ & phage display $^{c}$ \\
\hline 2 & Ac-HVNTYMWDGRYMRTSH-NH ${ }_{2}$ & 1.0 & & phage display ${ }^{c}$ \\
\hline 3 & H-NWAPAQHGQKWYMQDYTSLE-NH ${ }_{2}$ & 3.8 & & phage display ${ }^{a}$ \\
\hline 4 & H-TSNTTPWQTSWELMYAQQNY-NH 2 & 1.6 & & phage display ${ }^{d}$ \\
\hline 5 & H-KPHTYINDHNFIQYDNQQWL-NH & not soluble & & phage display ${ }^{a}$ \\
\hline 6 & H-YVTHPWIDWWDNEPYM-NH ${ }_{2}$ & not soluble & & phage display ${ }^{a}$ \\
\hline 7 & H-GHHHRVYMTDVTEHFRWMGK-NH ${ }_{2}$ & 0.6 & & phage display \\
\hline 8 & H-GHHHRVYMTDVTEHFRWWVN-NH ${ }_{2}$ & 0.5 & & phage display ${ }^{d}$ \\
\hline 9 & TAMRA-HAKTYMWDGWYMPTSH-NH ${ }_{2}$ & not tested & $52 \pm 3 \mu \mathrm{M}$ & optimization \\
\hline 10 & Ac-TYMWDGWYMPT-NH${ }_{2}$ & 4.5 & & optimization \\
\hline 11 & Ac-YMWDGWYM-NH ${ }_{2}$ & 6.9 & & optimization \\
\hline 12 & {$[\mathrm{PEG}]_{6}$-YMWDGWYM-NH${ }_{2}^{e}$} & 6.2 & $26 \pm 4 \mu \mathrm{M}$ & optimization \\
\hline 13 & {$[\mathrm{PEG}]_{6}-\mathrm{YMWDGW}-\mathrm{OH}^{e}$} & 0.3 & & optimization \\
\hline 14 & {$[\mathrm{PEG}]_{6}$-YMWDGW-NH${ }_{2}{ }^{e}$} & 0.5 & & optimization \\
\hline 15 & H-WDGWYM- $[\mathrm{PEG}]_{6}^{e}$ & 0.3 & & optimization \\
\hline 16 & Ac-WDGWYM- $[\mathrm{PEG}]_{6}^{e}$ & 0.3 & & optimization \\
\hline 17 & {$[\mathrm{PEG}]_{6}-\mathrm{YMWEGWYM-OH}{ }^{e}$} & 4.8 & & optimization \\
\hline 18 & {$[\mathrm{PEG}]_{6}-\mathrm{YM}(\mathrm{Nal}) \mathrm{DGWYM}-\mathrm{OH}^{e_{f} f}$} & 2.8 & & optimization \\
\hline
\end{tabular}

${ }^{a} \alpha$-Cbtx $(40 \mathrm{nM})$ inhibited ACh $(100 \mu \mathrm{M})$ gated currents through nAChRs to $8 \pm 2 \%$ their control level, which is here normalized to 1.0 . In the presence of, e.g., peptide $1(100 \mu \mathrm{M}), \alpha$-Cbtx $(40 \mathrm{nM})$ only inhibited ACh $(100 \mu \mathrm{M})$ gated currents to $60 \pm 18 \%$ of control, here normalized to 7.4-fold prevention of inhibition. ${ }^{b} K_{\mathrm{d}}$ value of 9 determined in fluorescence polarization (FP) saturation experiment $(n=2)$. $K_{\mathrm{i}}$ values for peptides 1 and 12 determined by inhibition of 9 binding to $\alpha$-Cbtx in FP competition experiments $(n=6)$, only measured for two lead peptides. ${ }^{c}$ After five rounds of selection by biopanning. ${ }^{d}$ From deep sequencing of all phages. ${ }^{e} \mathrm{PEG}$, polyethylene glycol. ${ }^{f} \mathrm{Nal}$, 3 -(2-naphthyl)-L-alanine.
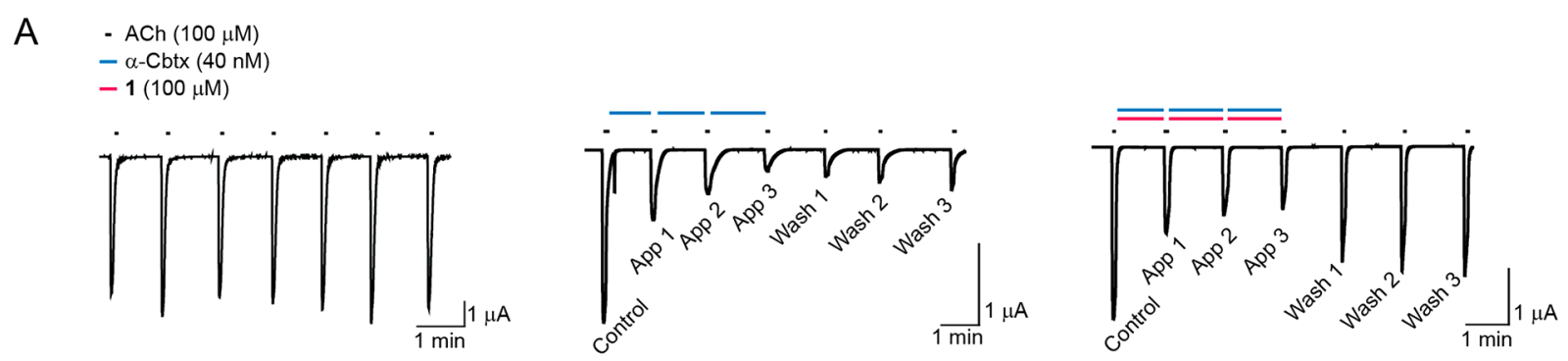

B
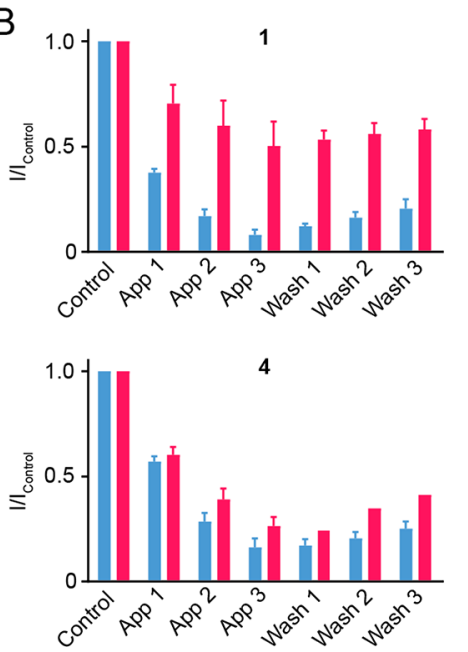
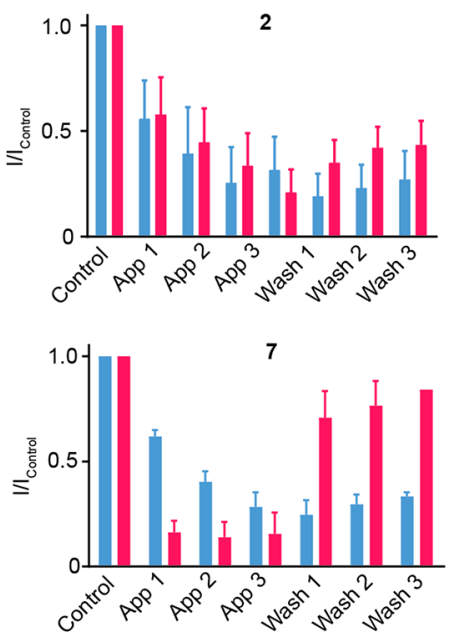
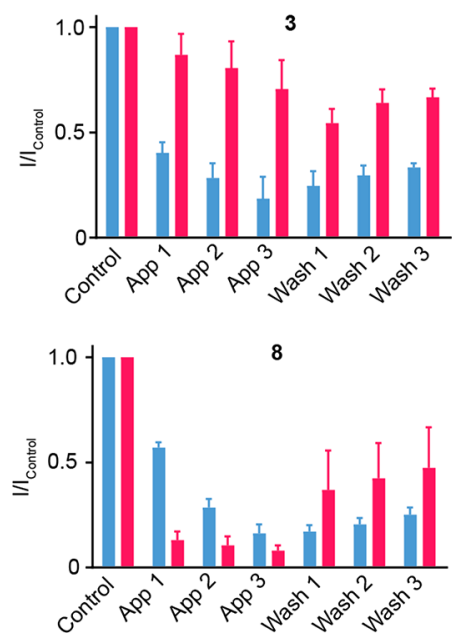

Figure 1. Peptide 1 prevents $\alpha$-Cbtx inhibition of nAChRs. (A) Example two electrode voltage clamp recordings of ACh-gated currents in Xenopus laevis oocytes expressing L247V mutant $\alpha 7 \mathrm{nAChRs}$ and RIC-3 (see Experimental Section, Electrophysiological Assays). In testing peptides, ACh was applied for $10 \mathrm{~s}$ in regular conditions ("control"), three times after the application of either $\alpha$-Cbtx (blue bars) or $\alpha$-Cbtx with peptide (blue and magenta bars; "App 1-App 3"), and then three more times to observe washout of any effects ("Wash 1-Wash 3"). (B) Mean \pm SEM ACh-gated current amplitude, normalized to control ("I/I $I_{\text {control }}$ "). Each peptide was tested with $\alpha$-Cbtx on at least three oocytes: $n$ (magenta columns) $=3-4$. $\alpha$ Cbtx alone was tested on the same day on at least two oocytes: $n$ (blue columns) $=2$ (peptides 1 and 2 ) -4 (all others). 


\section{RESULTS}

High-Throughput Identification of Peptide Binders of $\alpha$-Cbtx. Seeking novel binders of $\alpha$-Cbtx, we screened naïve phage display libraries containing $\geq 1 \times 10^{9}$ disulfide-constrained 7-mers and linear 7-mers, 12-mers, 16-mers, or 20-mers against immobilized $\alpha$-Cbtx from Naja kaouthia (monocled cobra). Isolation and sequencing of the most prevalent phages after five rounds of biopanning identified two 16-mers, peptides 1 and $\mathbf{2}$ (Table 1). Additionally, deep sequencing of phages from all rounds identified six additional prevalent peptides, $3-8$, that were also considered further (Table 1; see Experimental Section).

Characterization of Peptides with YM Motifs That Modulate $\alpha$-Cbtx Inhibition of Nicotinic Acetylcholine Receptors. We next tested these binders for functional modulation of $\alpha$-Cbtx activity in electrophysiological assays. We heterologously expressed nicotinic $\alpha 7$-homomeric nAChRs in Xenopus laevis oocytes and measured acetylcholine-gated currents in response to acetylcholine alone, in the presence of $\alpha$ Cbtx, or in the presence of $\alpha$-Cbtx preincubated with the identified peptides. As expected, $\alpha$-Cbtx alone (40 nM) inhibited $\mathrm{nAChR}$ responses to $\sim 10 \%$ compared to the control level, and washout of this effect was minimal, with subsequent responses to ACh in the absence of $\alpha$-Cbtx recovering to only $20 \%$ (Figure $1 \mathrm{~A}, \mathrm{~B})$. In the presence of peptide $1(100 \mu \mathrm{M}), \alpha$ Cbtx $(40 \mathrm{nM})$ only inhibited responses to $\sim 50 \%$ of the control level, with responses after washout reaching $70 \%$ (Figure 1A,B). Peptide 1 thus appears to prevent the effects of $\alpha$-Cbtx. Peptide 2 had no effect on $\alpha$-Cbtx inhibiting nAChRs (Figure 1B). Among the six additional binders, peptide 3 prevented $\alpha$-Cbtx inhibition of nAChRs comparably to 1 (Figure 1B). However, peptide $\mathbf{4}$ showed no effect (Figure 1B), and peptides 5 and $\mathbf{6}$ were poorly soluble and could not be tested. Curiously, peptides 7 and 8 enhanced both the onset and the washout of $\alpha$-Cbtx inhibition of nAChRs (Figure 1B). Thus, for two of the eight $\alpha$ Cbtx binders identified by phage display, the desired effect of preventing $\alpha$-Cbtx inhibition of nAChRs could be demonstrated, and the shorter peptide $\mathbf{1}$ was chosen for the further investigations.

We next established the dose-dependency of the effects of 1 on $\alpha$-Cbtx in our electrophysiological assay. The initial protection from $\alpha$-Cbtx inhibition (" $I_{\mathrm{App} 3} / I_{\text {Control }}$ ) occurred at concentrations of 1 in the range $30-100 \mu \mathrm{M}$, whereas apparent enhancement of $\alpha$-Cbtx washout (" $I_{\text {Wash } 3} / I_{\text {Control }}$ ) occurred at concentrations of 1 between 3-30 $\mu \mathrm{M}$ (Figure 2A). To better estimate binding affinity, we turned to a fluorescence polarization (FP) assay, for which we generated peptide 9, a rhodamine dye-labeled derivative of peptide 1 (Figure 2C). From incubating 9 in increasing concentrations of $\alpha$-Cbtx, we determined the dissociation constant for the $\alpha$-Cbtx -9 interaction $\left(K_{\mathrm{d}} 52 \pm 3 \mu \mathrm{M}, n=2\right.$, Figure $\left.2 \mathrm{D}\right)$. By incubating premixed $\alpha$-Cbtx $(40 \mu \mathrm{M})$ and $9(50 \mathrm{nM})$ with increasing concentrations of 1 , we determined an $\mathrm{IC}_{50}$ value of $29 \pm 6 \mu \mathrm{M}$ for compound $\mathbf{1}(n=6$, Figure $2 \mathrm{E})$, corresponding to a $K_{\mathrm{i}}$ value of $1.9 \mu \mathrm{M}$ (see Experimental Section, Fluorescence Polarization Assay). Regarding concentrations of $\mathbf{1}$ that elicited functional effects, this $K_{\mathrm{i}}$ is more consistent with the enhanced washout of $\alpha$-Cbtx than with the prevention of $\alpha$-Cbtx inhibition.

Peptide Aromatic Side Chains Bind to $\alpha$-Cbtx Key Residues R33 and D27. Seeking insight into the peptide $-\alpha$ Cbtx interaction, we turned to structure determination by X-ray crystallography. This required improved peptide solubility, and
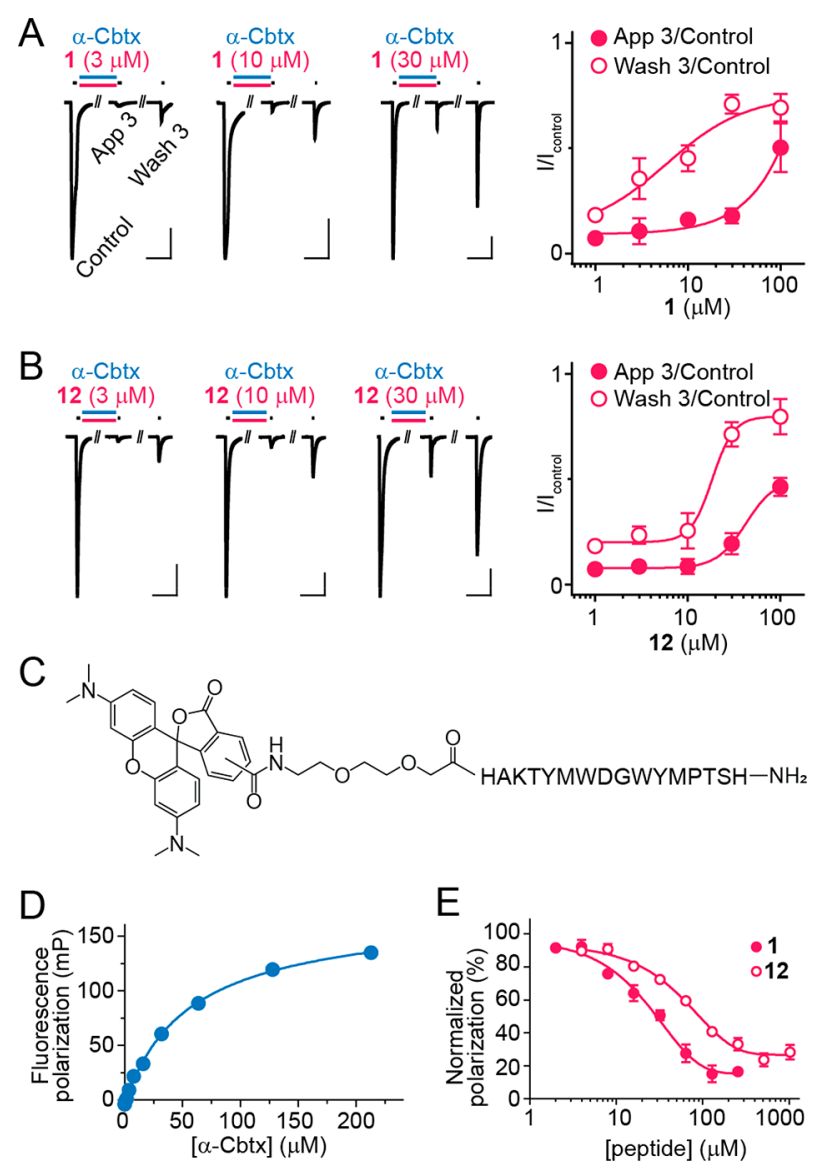

Figure 2. Concentration dependence of peptide activity. (A,B) Electrophysiological experiments as per Figure 1A, but here only initial ACh application ("Control"), the third ACh application after peptide + $\alpha$-Cbtx (40 nM) ("App 3"), and the third ACh application after washout ("Wash 3") are shown. Mean $\pm \operatorname{SEM}(n=3)$ are shown to the right. (C) Chemical structure of 9. (D) Fluorescence polarization of 9 (50 $\mathrm{nM}$ ) by increasing concentrations of $\alpha$-Cbtx. Mean \pm SEM, $n=2$. (E) Concentration-dependent displacement of $9(50 \mathrm{nM})$ from $\alpha$-Cbtx $(40 \mu \mathrm{M})$ by compound 1 and 12 . Mean \pm SEM, $n=6$.

we therefore designed and tested truncated (peptides 10 and 11 ) and truncated, polyethylene glycolated ( $\mathrm{PEG}_{6}$-ylated, peptides 12-16) derivatives of $\mathbf{1}$ (Table 1 , Supporting Information, Figure S1). The $\mathrm{PEG}_{6}$-ylated 8-mer, peptide 12, exhibited similar potency to $\mathbf{1}$ in electrophysiological assays, with $12(100 \mu \mathrm{M})$ restoring $\alpha$-Cbtx $(40 \mathrm{nM})$ inhibited AChgated currents from $\sim 10 \%$ to $\sim 50 \%$ (Figure $2 \mathrm{~B}$ ). In the FP assay, 12 outcompeted 9 from $\alpha$-Cbtx similarly to 1 , despite slightly reduced affinity compared to $1\left(12 K_{\mathrm{i}}=26 \pm 4 \mu \mathrm{M}, n=\right.$ $6, P<0.003$, Figure $2 \mathrm{E}$ ). We also observed increased stability of 12 compared to 1 at both room temperature and at $37{ }^{\circ} \mathrm{C}$ (Supporting Information, Figure S2). Given the similar functional properties but improved solubility of 12 , it was used for X-ray crystallography.

We obtained diffraction-quality cocrystals and solved the Xray crystal structure of the 12: $\alpha$-Cbtx complex at $1.9 \AA$ resolution (Supporting Information, Table S1). The asymmetric unit contains four copies of $\alpha$-Cbtx and two copies of $\mathbf{1 2}$ (Figure 3A). One molecule of $\mathbf{1 2}$ binds to two toxin molecules (designated $\alpha$-Cbtx-A and $\alpha$-Cbtx-B), forming a 1:2 complex (Figure 3A, Supporting Information, Figure S3). The two $\alpha$ Cbtx-A:12: $\alpha$-Cbtx-B complexes present in the asymmetric unit are related by noncrystallographic symmetry and highly similar 

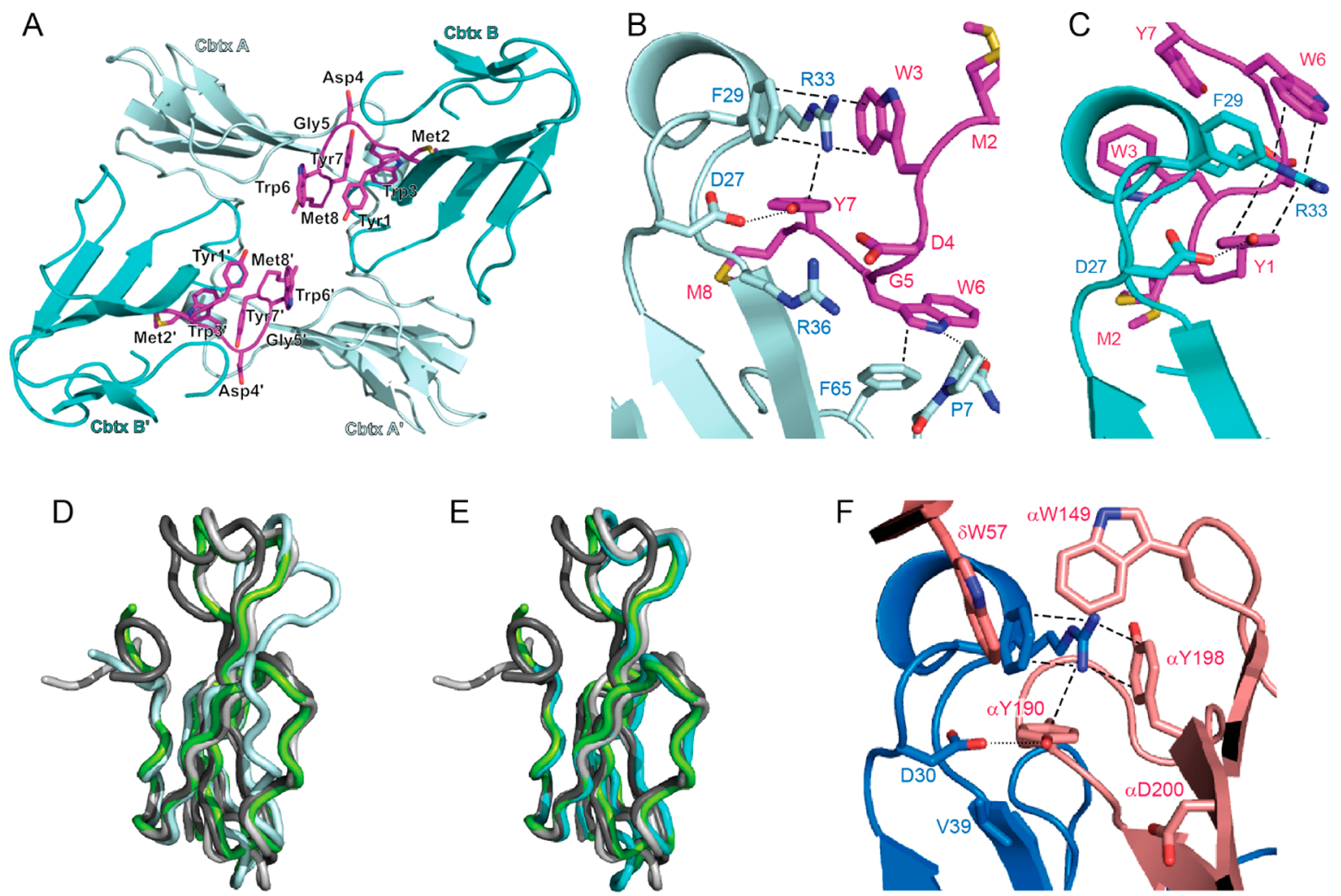

Figure 3. Structure of the 12: $\alpha$-Cbtx complex (PDB 6ZFM). (A) Asymmetric unit of the 12: $\alpha$-Cbtx crystal structure. Each molecule of 12 (magenta) binds two toxin molecules A and B (light and dark cyan, respectively). A second $\alpha$-Cbtx-A:12: $\alpha$-Cbtx-B complex in the asymmetric unit is related by noncrystallographic symmetry. (B) Magnified view showing interaction of $\alpha$-Cbtx loop II (light cyan) with 12 (magenta) in binding mode A. Two alternative conformations for the side chain of ${ }^{12} \mathrm{M} 2$ were modeled. Key interacting amino acid residues shown in stick representation and labeled. Cation $-\pi$-stacking interactions and hydrogen bonds are highlighted by dashed and dotted lines, respectively. (C) Binding mode $\mathrm{B}$, with second $\alpha$-Cbtx molecule (dark cyan), from same structure with interacting residues drawn as in (B). (D) Binding mode A leads to conformational changes in $\alpha$-Cbtx (light cyan) compared to the structure observed of $\alpha$-Cbtx from Naja naja siamensis (dark gray, PDB 2CTX, root-mean-square deviation (rmsd) 1,31 $\AA$ ), Naja naja oxania (light gray, PDB 1NTN, rmsd $1.7 \AA$ ), or Naja naja kaouthia in complex with AChBP (green, PDB 1YI5, rmsd $1.47 \AA$ ). The greatest displacement is observed in loop II (11 $\AA$ ) and loop III $(4.7 \AA$ ). (E) Binding mode B (cyan) resembles more closely previously reported structures of $\alpha$-Cbtx from Naja naja siamensis (dark gray, rmsd 1,07 $\AA$ ), Naja naja oxania (light gray, rmsd $0.67 \AA$ ), or Naja naja kaouthia in complex with AChBP (green, rmsd $0.87 \AA$ ). (F) Interaction of $\alpha$-Bgtx (blue) loop II with the principal ( $\alpha$ subunit) and complementary $(\delta$ subunit) faces of the muscle nAChR (pink, PDB 6UWZ). Key interacting residues drawn as in (B).

to a root mean square deviation (rmsd) of $0.2 \AA$. Thus, we observed two different binding modes of $\mathbf{1 2}$ with $\alpha$-Cbtx (Figure 3B,C). Whereas the structure of $\alpha$-Cbtx-B is very similar to the conformation of $\alpha$-Cbtx observed in previous crystal structures, 12 binding induces substantial structural rearrangements of loop II and indirectly also of loop III in $\alpha$-Cbtx-A (Figure 3D,E). The formation of a 1:2 12: $\alpha$-Cbtx complex was surprising considering that $\mathbf{1 2}$ was added in 1.2-fold molar excess in the crystallization set-ups. This raises the possibility that the mechanism of $\alpha$-Cbtx inhibition by 12 involves inducing toxin dimerization. There is very little contact between the two $\alpha$-Cbtx molecules themselves in the complex $\left(52 \AA^{2}\right)$ as determined by computational analysis (PISA), ${ }^{17}$ suggesting that these interactions do not contribute to the stabilization of the complex. We reasoned that if both motifs A and B were acting independently as inhibitors, they should prevent $\alpha$-Cbtx inhibition of nAChRs on their own. However, shorter peptides designed to include only binding motif A (peptides 13 and 14) or motif B (peptides 15 and 16) did not have any effect on $\alpha$-Cbtx activity in electrophysiological assays (Table 1, Supporting Information, Figure S1). We therefore tentatively conclude that the simultaneous binding of $\mathbf{1 2}$ to two $\alpha$-Cbtx molecules leads to a mutual stabilization of both interfaces or that peptide 12 blocks
$\alpha$-Cbtx by linking two $\alpha$-Cbtx molecules and preventing them from further binding to nAChRs. However, analysis of 12induced dimerization of $\alpha$-Cbtx in solution by size exclusion chromatography was not possible due to the high hydrophobicity of the peptide, which led to aggregation on the gel filtration column.

Although binding modes A and B are distinct, they share common features (Figure 3B,C, Table 2). (i) Two different YM

Table 2. Key Residues of the 12- $\alpha$-Cbtx Interaction (PDB 6ZFM) in Comparison to the nAChR- $\alpha$-Bgtx Complex

\begin{tabular}{|c|c|c|c|c|}
\hline $\begin{array}{c}\alpha- \\
\text { Cbtx }\end{array}$ & 12-A & 12-B & $\begin{array}{c}\alpha- \\
\text { Bgtx }\end{array}$ & $\begin{array}{l}\text { nAChR (PDB } \\
\text { 6UWZ) }\end{array}$ \\
\hline D27 & Y7 (H bond) & Y1 (H bond) & D30 & $\alpha \mathrm{Y} 190$ (H bond) \\
\hline F29 & & $\mathrm{W} 6(\pi-\pi)$ & F32 & $\begin{array}{c}\gamma \mathrm{W} 55 / \delta \mathrm{W} 57, \alpha \mathrm{W} 149 \\
\text { (hydrophobic) }\end{array}$ \\
\hline R33 & $\begin{array}{l}\text { W3, Y7 } \\
\quad(\text { cation }-\pi)\end{array}$ & $\begin{array}{l}\text { Y1, W6 } \\
\quad(\text { cation }-\pi)\end{array}$ & R36 & $\begin{array}{l}\text { Y190 } \alpha, \mathrm{Y} 198 \alpha \\
\quad(\text { cation }-\pi) ; \gamma \mathrm{W} 55 / \\
\delta \mathrm{W} 57, \alpha \mathrm{W} 149 \\
\text { (hydrophobic) }\end{array}$ \\
\hline $\mathrm{R} 36$ & D4 (salt bridge) & $\begin{array}{l}\text { Y1 (hydrophobic) } \\
\text { (hic }\end{array}$ & V39 & \\
\hline F65 & $\begin{array}{l}\text { W6 } \\
\text { (hydrophobic) }\end{array}$ & & H68 & backbone (H-bond) \\
\hline
\end{tabular}


motifs bind at equivalent positions in binding mode $\mathrm{A}$ and $\mathrm{B}$, forming a hydrogen bond between ${ }^{12} \mathrm{Y} 7$ or ${ }^{12} \mathrm{Y} 1$ and ${ }^{\alpha-\mathrm{Cbtx}} \mathrm{D} 27$ and interacting with the surface of $\alpha$-Cbtx at the beginning of loop II. (ii) Using different aromatic residues, modes A and B both create, together with ${ }^{\alpha-\mathrm{Cbtx}} \mathrm{F} 29$, an aromatic pocket for ${ }^{\alpha-C b t x} \mathrm{R} 33$ through extensive cation $-\pi$ stacking interactions of parallel and T-shaped geometry (Figure 3B,C). Thus, the key residue ${ }^{\alpha \text {-Cbtx }} \mathrm{R} 33$ that has been implicated in penetrating the ACh binding pocket of $\mathrm{nAChRs}^{18}$ is tightly blocked by 12 in both binding modes. In binding mode $\mathrm{A}$, a tryptophan residue that precedes the YM motif also interacts with ${ }^{\alpha-\mathrm{Cbtx}} \mathrm{F} 65$ at the Cterminus of $\alpha$-Cbtx and forms a hydrogen bond to the backbone carbonyl of ${ }^{\alpha-\mathrm{Cbtx}} \mathrm{P} 7$ (Figure 3B). Exchange of this tryptophan for arginine (along with three other substitutions) in peptide $\mathbf{2}$ led to a loss of the preventive activity of the peptide (Table 1, Figure 1B), underscoring the functional importance of this tryptophan residue.

The Inhibitory Peptide Mimics the $\alpha$-Cbtx Interaction Site and Binding Mode of the nAChR. The structure of the nAChR: $\alpha$-Cbtx complex has not been determined, but the structure of the muscle-type (heteromeric $\alpha-\gamma-\alpha-\delta-\beta$ ) nAChR: $\alpha$-Bgtx complex was recently reported. ${ }^{19}$ Because $\alpha$ Cbtx and $\alpha$-Bgtx share high sequence and structural homology, ${ }^{18}$ we can use the nAChR: $\alpha$-Bgtx complex to compare $\alpha$-Cbtx interactions with the peptide inhibitor to those with its native target (Figure 3F). The nAChR: $\alpha$-Bgtx interaction is much more extensive $\left(\sim 1100 \AA^{2}\right)$ compared to the 12: $\alpha$-Cbtx complex $\left(\sim 440 \AA^{2}\right.$ in mode $A$ and $\sim 510 \AA^{2}$ in mode $\left.B\right)$, but interestingly, the peptide inhibitor 12 partially mimics the binding site of the natural substrate. Most strikingly, ${ }^{12} \mathrm{Y} 1$ (in binding mode $\mathrm{B}$ ) and ${ }^{12} \mathrm{Y} 7$ (in binding mode $\mathrm{A}$ ) adopt the same position as ${ }^{\mathrm{nAChR} \alpha} \mathrm{Y} 190$, which forms a conserved hydrogen bond with ${ }^{\alpha \text {-Cbtx }} \mathrm{D} 27$ and ${ }^{\alpha-\mathrm{Bgtx}} \mathrm{D} 30$, respectively (Table 2 ). This interaction is also conserved in the complex of $\alpha$-Cbtx with the acetylcholine binding protein $(\mathrm{AChBP}),{ }^{20}$ where ${ }^{\mathrm{AChBP}} \mathrm{Y} 185$ binds ${ }^{\alpha-C b t x} \mathrm{D} 27$ (Supporting Information, Figure S4A). The similarity between 12 and $\mathrm{nAChR}$ is also apparent in the pocket for ${ }^{\alpha-C b t x} \mathrm{R} 33 /{ }^{\alpha-\mathrm{Bgtx}} \mathrm{R} 36$ and ${ }^{\alpha-\mathrm{Cbtx}} \mathrm{F} 29 /{ }^{\alpha-\mathrm{Bgtx}} \mathrm{F} 32$ in binding mode $\mathrm{A}$, which is formed by aromatic side chains ${ }^{12} \mathrm{~W} 3 /{ }^{12} \mathrm{Y} 7$ in 12-A and ${ }^{\mathrm{nAChR} \alpha} \mathrm{Y} 190 /{ }^{\mathrm{nAChR} \alpha} \mathrm{Y} 198$ in the $\mathrm{nAChR}$. In contrast, ${ }^{12} \mathrm{Y} 1 /{ }^{12} \mathrm{~W} 6$ in $12-\mathrm{B}$ are also engaged in cation $-\pi$ interactions with ${ }^{\alpha-\mathrm{Cbtx}} \mathrm{R} 33$, but the orientations of side chains differ from nAChR: $\alpha$-Bgtx. The aromatic pocket for ${ }^{\alpha-\mathrm{Bgtx}} \mathrm{R} 36$ is closed by $\mathrm{y}^{\mathrm{nAChR} \gamma} / \mathrm{W} 55 /{ }^{\mathrm{nAChR} \gamma} \delta \mathrm{W} 57$ and ${ }^{\mathrm{nAChR} \alpha} \mathrm{W} 149$ through hydrophobic interaction, which lacks a counterpart in the 12: $\alpha$-Cbtx complex. It is also interesting to note that aspartate ${ }^{\mathrm{nAChR} \alpha} \mathrm{D} 200$ superposes with ${ }^{12} \mathrm{D} 4$ of binding mode A. ${ }^{\mathrm{nAChR} \alpha} \mathrm{D} 200$ does not play a role in $\alpha$-Bgtx binding to the receptor, but the substitution of ${ }^{\alpha \text {-Bgtx }} \mathrm{V} 39$ to ${ }^{\alpha \text {-Cbtx }} \mathrm{R} 36$ likely leads to the formation of a salt bridge upon binding of $\alpha$-Cbtx to the $\mathrm{nAChR}$. Thus, ${ }^{12} \mathrm{D} 4$ would further imitate the target binding site. Taken together, the structural comparison reveals that the phage display selection provided a peptide that blocks the binding site of $\alpha$-Cbtx by imitating the cognate interface through an unrelated sequence.

\section{DISCUSSION}

The urgent need for alternatives to conventional antivenom for snakebite has given rise to a handful of novel approaches, including camelid- and human-derived antibodies that target particular venom components, ${ }^{14-16,21}$ nanoparticles to adsorb plasma proteins, ${ }^{22}$ and small molecules or peptides to inhibit key components of venom. ${ }^{23,24}$ Smaller peptides are likely cheaper than traditional antivenom and may lead to more convenient and effective drugs that can be injected subcutaneously. ${ }^{7,25}$ Consequently, we pursued the idea that short, synthetic peptides inhibiting critical toxin-receptor interactions could serve as lead compounds for the development of novel peptide-based antivenoms. Furthermore, our results suggest that such small peptides are conducive to crystallization and rational design and could be useful for the academic community as pharmacological tools. Starting from some five billion 7-mers, 12-mers, 16-mers, and 20-mers, we arrived at an 8-mer that prevents $\alpha$-Cbtx from inhibiting nicotinic nAChRs.

Our initial search identified eight peptides that bound $\alpha$-Cbtx. Despite the absence of primary sequence homology with nAChRs, each peptide contained at least one YM motif. The tyrosine forms a hydrogen bond to ${ }^{\alpha-\mathrm{Cbtx}} \mathrm{D} 27$, and this $\mathrm{Y}-\mathrm{D}$ bond is conserved in both peptide binding modes that we observed in AChBP: $\alpha$-Cbtx and nAChR: $\alpha$-Bgtx structures ${ }^{19,20}$ and also in a nAChR-like 13 -mer binding to $\alpha$-Bgtx ${ }^{26}$ (Supporting Information, Figure S4B), suggesting that this tyrosine residue represents an essential feature for $\alpha$-Cbtxbinding peptides. The methionine occupies a unique binding site at the base of $\alpha$-Cbtx loop II that might be exploited in future optimizations. Remarkably, the YM motif is flanked by a tryptophan in the two peptides (and derivatives thereof) that had the desired effect of preventing nAChR inhibition by $\alpha$ Cbtx. The YM sequence in combination with an upstream or downstream tryptophan residue thus represents a novel motif that might serve as a scaffold for designing future peptide inhibitors or peptide-derived small molecule inhibitors of $\alpha$ Cbtx. Simultaneous binding of our inhibitor to two $\alpha$-Cbtx molecules seems to be required for functionality. This is evident in the inhibition of $\alpha$-Cbtx by peptides $1,10,11$, and 12, which contain both motifs $A$ and $B$ of 12, while peptides 13-16, which contain either motif A or motif B of 12, fail to inhibit $\alpha$-Cbtx. We suspect that binding of two $\alpha$-Cbtx molecules results in stabilization of the peptide conformation. Introducing dimerization of $\alpha$-Cbtx might also be part of the inhibitory mechanism of the identified peptides. Thus, strategies to rigidify the two identified epitopes might be employed for improved activity.

Optimization will also require improved affinity for $\alpha$-Cbtx, as half-maximal effective concentrations and $K_{\mathrm{i}}$ values for our 8mer, 16-mer, and 20-mer inhibitors were in the low micromolar range. Much greater affinity for $\alpha$-Bgtx was seen with previously studied 13 -mers, ${ }^{24}$ possibly due to greater stability through the additional intramolecular hydrogen bonds afforded by the $\beta$ hairpin structure of those peptides. Although also identified through phage display, those peptides bear striking similarity to the principal face of nAChRs. ${ }^{24}$ Our identification of a nAChRunrelated sequence with a mimicking effect opens up entirely new avenues for future work. It is also noteworthy that, in addition to inhibitors of $\alpha$-Cbtx, we also identified enhancers of $\alpha$-Cbtx activity, tentatively suggesting that toxin activity can be manipulated by peptides via distinct mechanisms. The desired improvement of affinity of $\mathbf{1}, \mathbf{1 2}$, and similar molecules from the present study may be possible through subtle modifications. In limited structure-activity relationship experiments, we observed that single substitutions of D4 and W3 to glutamic acid and naphthylalanine, respectively, yielded two peptides, 17 and 18, that retained the inhibitory effect on $\alpha$-Cbtx (Table 1, Supporting Information, Figure S1B). Tolerance of isofunctional substitutions at W3 and D4, which indeed interact with ${ }^{\alpha \text {-Cbtx }} \mathrm{R} 33$ and ${ }^{\alpha \text {-Cbtx }} \mathrm{R} 36$ (Figure 3B), suggests some scope for optimization at these positions. 
That PEGylation was also well tolerated could prove useful in future antivenom drug development. Weaknesses of peptidebased drugs include short in vivo half-life/rapid elimination and poor membrane permeability. ${ }^{25}$ However, these can sometimes be overcome by increasing molecular mass via PEGylation and conjugation to larger peptides or other moieties. ${ }^{27-29}$ The fact that the YMWDGWYM motif was effective on its own (as 11), PEGylated (as 12), straddled by other residues (in 1), or even as a divergent, longer peptide (as 3) is also promising when considering typical approaches to improve stability and membrane permeation, such as cyclization, stapling, and conjugation. ${ }^{30,31}$ Our measurements of peptides 1 (free peptide) and 12 (PEGylated) in phosphate-buffered saline show that both are reasonably stable over the course of 1 day, and notably, the purity of 12 was decreased by just $7 \%$ after incubation for 9 days at room temperature or 2 days at $37{ }^{\circ} \mathrm{C}$ (Supporting Information, Figure S2).

\section{CONCLUSION}

Current therapies for snakebite envenoming are difficult to produce, far too inaccessible for those in need, and often cause adverse reactions. ${ }^{1,32}$ We speculate that a combination of several peptides targeting the key venom components will provide simpler, more distributable, safer, and subcutaneous- and/or intramuscular-capable alternatives to conventional antivenom, or at least a feasible short-term solution that prevents excess toxin from reaching nAChRs immediately after snakebite. Our report on the identification of such snake toxin-binding peptides, which we term "serpentides", 33 the characterization of their effects on the physiological action of the toxin, and the highresolution structural characterization of the peptide-toxin interaction should facilitate future endeavors in developing such molecules into therapies.

\section{EXPERIMENTAL SECTION}

Phage Display Screening. Maleic anhydride activated 96-well plates (ThermoFisher Scientific) wells were incubated with $100 \mu \mathrm{L}$ of $10.0 \mu \mathrm{M} \alpha$-cobratoxin ( $\geq 99 \%$, from Naja kaouthia, Latoxan) in phosphate buffered saline (PBS) or PBS alone (as control), capped with $200 \mu \mathrm{L} 10 \%(\mathrm{v} / \mathrm{v})$ ethanolamine, for $1 \mathrm{~h}$ at room temperature (RT, $\sim 21$ ${ }^{\circ} \mathrm{C}$ ) and then overnight at $4{ }^{\circ} \mathrm{C}$. Subsequently, the wells were washed $3 \times$ with $200 \mu \mathrm{L}$ of $0.05 \%$ Tween-20 (PBST) and $2 \times$ with $200 \mu \mathrm{L}$ of PBS. Wells were then blocked by incubation in $100 \mu \mathrm{L}$ blocking buffer $\left(0.1 \mathrm{M} \mathrm{NaHCO}_{3} \mathrm{pH}\right.$ 8.6, $0.02 \% \mathrm{NaN}_{3}, 0.1 \mu \mathrm{g} / \mathrm{mL}$ streptavidin (incidental, as the selection process did not utilize biotinylation), $5 \mathrm{mg}$ / $\mathrm{mL}$ bovine serum albumin at RT on a plate shaker for $2 \mathrm{~h}$. Wells were then washed $10 \times$ with PBST and $2 \times$ with PBS to remove excess blocking agent.

For the first biopanning round, $2.5 \mu \mathrm{L}$ of both TriCo- 16 and TriCo20 libraries (Creative Biolabs) were combined in $105 \mu \mathrm{L}$ of blocking buffer and incubated for $30 \mathrm{~min}$ at RT. This phage solution $(100 \mu \mathrm{L})$ was transferred to a blocked but not $\alpha$-cobratoxin-coated MaxiSorp plate and incubated for $1 \mathrm{~h}$ at RT to remove unspecific binding phages. Unbound phage $(100 \mu \mathrm{L})$ was then transferred to the $\alpha$-cobratoxincoated wells and incubated for $1 \mathrm{~h}$ at RT. The solution was then removed, and wells were washed 10x PBST and $2 \times$ with PBS. Bound phages were eluted by incubating for $10 \mathrm{~min}$ with triethylamine $(200$ $\mu \mathrm{L}, 100 \mathrm{mM})$ followed by neutralization with a solution of Tris- $\mathrm{HCl}$ (400 $\mu \mathrm{L}, 1 \mathrm{M}, \mathrm{pH}$ 7.4). Before each of four subsequent rounds of selection, the eluted phages were amplified in $2 \mathrm{XYT}$ medium $(8-10$ $\mathrm{mL}$ ) overnight at $37^{\circ} \mathrm{C}$ after infecting TG1 Escherichia coli. Amplified phages were precipitated using $\mathrm{PEG}_{6000} / \mathrm{NaCl}$ and concentrated in $\mathrm{PBS}$ $(300 \mu \mathrm{L})$. Phages $(115 \mu \mathrm{L})$ mixed with blocking buffer were incubated for $1 \mathrm{~h}$ in a MaxiSorp well before the next round of panning. The specific binder/control ratios (based on numbers of plaque forming units) were
$24,203,755$, and 175 for rounds two through five, indicating that specific $\alpha$-Cbtx binders had been amplified (except in the final round).

Twenty-four single plaques were picked and amplified overnight, centrifuged for $10 \mathrm{~min}$ at $8000 \mathrm{~g}$, and $125 \mu \mathrm{L}$ supernatant was added to $\alpha$-Cbtx-coated wells for overnight incubation. The solution was then removed, and wells washed, blocked, and washed again, and each eluate (100 $\mu \mathrm{L}$ in PBS) was mixed $1: 1$ with blocking buffer. $100 \mu \mathrm{L}$ was added to $\alpha$-Cbtx-coated (or control) wells, incubated for $1 \mathrm{~h}$ at RT on a plate shaker, and then washed $10 \times$ with $100 \mu \mathrm{L}$ PBST and $2 \times$ with PBS. Bound phages were then incubated in $100 \mu \mathrm{L}$ of a solution of monoclonal horseradish peroxidase (HRP) conjugated anti-M13 phage antibody (GE Healthcare) diluted 1:100 in blocking buffer, for $1 \mathrm{~h}$ on a plate shaker, washed again $(10 \times$ with PBST, $2 \times$ with PBS), and each well was incubated in $100 \mu \mathrm{L}$ HRP substrate (ortho-phenylenediamine (OPD, Dako, $2 \mathrm{mg}$ in $3 \mathrm{~mL}$ water) with $5 \mu \mathrm{L} \mathrm{H}_{2} \mathrm{O}_{2}$ ) for $\sim 30 \mathrm{~min}$. Reactions were stopped by the addition of $100 \mu \mathrm{L}$ of $0.5 \mathrm{M} \mathrm{H}_{2} \mathrm{SO}_{4}$, and absorbance $(490 \mathrm{~nm})$ was measured (VersaMax Tunable microplate reader, Molecular Devices). Empty wells were used as blank controls for subtraction of signal. The 12 clones that gave the highest responses in the ELISA were selected for further processing. They were amplified overnight and $\mathrm{PEG}_{6000} / \mathrm{NaCl}$ precipitated. ssDNA was isolated and Sanger sequenced (Eurofins Genomics). Eleven encoded the same peptide, $\mathbf{1}$, and the remaining encoded 2 , which is $75 \%$ identical to $\mathbf{1}$ (Table 1).

Deep Sequencing of Phage Libraries and Selection of an Additional Six Peptides for Testing. Amplified phage eluates from biopanning rounds one, two, three, and five were used for deep sequencing of variable regions along with rounds two, three, four and five for the control selections. The libraries after those rounds were PCR amplified with barcoded primers (based on the above phage libraries and according to suppliers' instructions), gel purified, and sequencing adapters were ligated onto the DNA using the Ion Plus fragment library kit (ThermoFisher Scientific). Finally, the DNA was ligated to Ion Sphere Particles, subjected to emulsion PCR according to the Ion OneTouch 200 protocol. The Ion Sphere Particles were loaded onto an Ion 318 chip and sequenced in an Ion Torrent Personal Genome Machine system. The phage sequences were extracted, split according to barcodes and converted to peptide reads. For unknown reasons, the sequencing failed for the fifth biopanning round against $\alpha$ Cbtx as well as the second biopanning round for the control. The number of peptides allocated to these samples were $<400$ compared to $>100000$ for the remaining six samples. Accordingly, these samples were disregarded in further analyses. A total of $1,469,811$ sequences were obtained representing an average of 224,969 per sample (range $110503-499660$ ). The overall quality of the sequencing run was relatively low: if the quality (Phred) score cutoff was increased from 15 to 20 , the approved number of sequences dropped to 674,989 . Regarding the phage selection process, the number of unique peptides dropped with each subsequent round. Specifically, from 4938 to 410 for round one to three for the toxin-selected samples and similarly from 413 to 108 from rounds three to five in the control samples.

The most frequent peptide sequence identified in deep sequencing of the third selection round was identical to peptide 1 , a known binder from phage display/ELISA, suggesting that frequently occurring sequences in this round could be potential binders. Accordingly, three additional peptides (peptides 7, 3, and $\mathbf{5}$ in Table 1) ranking second through fourth in frequency in round three were selected for further studies. Another peptide, 8, was included because it ranked seventh in round three and was consistently prevalent in the later rounds. The most frequent peptide in the first selection round, 6 , was also selected. Finally, a peptide ranking sixth in the third round, 4, was included because it was highly similar to 8 differing only in $3 \mathrm{C}$-terminal amino acids out of the 20-mer peptide.

Electrophysiological Assays. Stage V/VI Xenopus laevis oocytes were prepared as described previously ${ }^{34}$ and under license 2014-150201-00031 from the Danish Veterinary and Food Administration. Oocytes were injected with a volume of $40 \mathrm{~nL}$ containing $4 \mathrm{ng}$ of cRNA for $\alpha 7$ nicotinic acetylcholine receptor (rat) carrying the L247V mutation to reduce desensitization ${ }^{35}$ and $4 \mathrm{ng}$ of cRNA for the chaperone RIC-3 (human), which enhances acetylcholine receptor 
function. ${ }^{36}$ cRNAs were prepared and oocytes were maintained as described previously. ${ }^{34}$ One to 3 days after injecting, two electrode voltage clamp recordings were made as follows: A single oocyte was transferred to a custom recording chamber ${ }^{37}$ and continuously perfused with bath solution (in mM; $96 \mathrm{NaCl}, 2 \mathrm{KCl}, 1.8 \mathrm{CaCl}_{2}, 1 \mathrm{MgCl}_{2}, 5$ HEPES, pH 7.4, with $\mathrm{NaOH}$ ). The oocyte was impaled with borosillicate glass micropipettes containing $3 \mathrm{M} \mathrm{KCl}$ (resistance $\sim 0.5-1.5 \mathrm{M} \Omega$ ), membrane voltage was clamped at $-40 \mathrm{mV}$, and current recorded with OC-725C amplifier (Warner Instruments), Digidata 1550 digitizer, and pClamp 10 Software (Molecular Devices) at $1 \mathrm{kHz}$ with $200 \mathrm{~Hz}$ filtering. Replicate experiments were generally performed on four individual oocytes (see Quantification and Statistical Analysis below). Solution exchange was performed with a ValveBank 8 perfusion system (AutoMate Scientific). ACh and $\alpha$-Cbtx were prepared from stocks dissolved in water $(100 \mathrm{mM}$ and $10 \mu \mathrm{M}$, respectively, stored at $-20^{\circ} \mathrm{C}$ ). Peptide $(1-18)$ stocks of $10 \mathrm{mM}$ were prepared in bath solution and typically used within 1 week (if not used in 1 day, these were stored at $-20^{\circ} \mathrm{C}$ ). Peptides were mixed with $\alpha$ Cbtx 20 min to $1.5 \mathrm{~h}$ before application to oocytes. Current amplitude was measured in Clampfit 10 (pClamp, Molecular Devices) and current amplitude was plotted and analyzed in GraphPad Prism 7.

Peptides. All peptides used for subsequent assays, except 9, were purchased from Schafer-N (Copenhagen, Denmark) or GenScript, $\geq 95 \%$ purity (Supporting Information, Figures S5-S22). The 5(6)carboxytetramethylrhodamine (TAMRA)-labeled peptide 9 was synthesized using an automated peptide synthesizer and standard Fmoc (fluorenylmethoxycarbonyl)-based solid-phase peptide synthesis (SPPS) on Rink amide TentaGel resin $(0.23 \mathrm{mmol} / \mathrm{g})$ at a $0.02 \mathrm{mmol}$ scale. Fmoc deprotections were performed in two steps: (1) piperidine in $\operatorname{DMF}(2: 3, \mathrm{v} / \mathrm{v})$ for $3 \mathrm{~min}$ and (2) piperidine in DMF $(1: 4, \mathrm{v} / \mathrm{v})$ for $12 \mathrm{~min}$. Deprotection steps were followed by washing with DMF $(2 \times$ $45 \mathrm{~s}), \mathrm{CH}_{2} \mathrm{Cl}_{2}(1 \times 45 \mathrm{~s})$, and DMF $(2 \times 45 \mathrm{~s})$. Coupling steps were performed as double couplings with Fmoc-Xaa-OH (5.00 equiv to the resin loading), 2-(1H-benzotriazol-1-yl)-1,1,3,3-tetramethyluronoium hexafluorophosphate (HBTU) (4.90 equiv), and $i-\mathrm{Pr}_{2} \mathrm{NEt}$ in NMP (10.0 equiv, $2.0 \mathrm{M}$ ) in DMF (final concentration $=0.2 \mathrm{M}$ for Fmoc-Xaa$\mathrm{OH})$ for $40 \mathrm{~min}$ for each coupling. Glycine was incorporated as $\mathrm{N}-\alpha-$ Fmoc- $N$ - $\alpha$-(2,4-dimethoxybenzyl)-glycine (Fmoc-(Dmb)Gly-OH). TAMRA-acid ( 1.50 equiv) was coupled manually using 2-(1H-7azabenzotriazol-1-yl)-1,1,3,3-tetramethyluronoium hexafluorphosphate (HATU) (1.50 equiv) and $i$ - $\mathrm{Pr}_{2} \mathrm{NEt}$ (3.00 equiv) in DMF (final concentration $=0.06 \mathrm{M}$ ) for $16 \mathrm{~h}$. Global deprotection and cleavage was conducted in the cleavage cocktail (TFA- $i-\mathrm{Pr}_{3} \mathrm{SiH}-$ water, 95:2.5:2.5, v/v/v) at room temperature (RT) for $2 \mathrm{~h}$, followed by TFA evaporation and ether precipitation. The crude peptide was purified as single isomer by preparative reverse-phase high performance liquid chromatography (RP-HPLC) on a C8 Phenomenex Luna column $(5 \mu \mathrm{m}, 100 \AA, 250 \mathrm{~mm} \times 20 \mathrm{~mm})$ using an Agilent $1260 \mathrm{LC}$ system. Fractions were analyzed by matrix assisted laser desorption ionization-time-of-flight mass spectrometry (MALDI-TOF MS), and pure fractions were pooled and lyophilized. Purity was determined using an Agilent 1100 system equipped with C18 Phenomenex Luna column $(2.6 \mu \mathrm{m}, 100 \AA, 150 \mathrm{~mm} \times 4.60 \mathrm{~mm})$. Analytical HPLC purity $95 \%(\lambda=215 \mathrm{~nm}$; Figure S13). UPLC-MS $\mathrm{m} / z$ calcd for $\mathrm{C}_{124} \mathrm{H}_{157} \mathrm{~N}_{27} \mathrm{O}_{30} \mathrm{~S}_{2}{ }^{2+}[\mathrm{M}+2 \mathrm{H}]^{2+}: 1284.55$, found 1284.38; $\mathrm{C}_{124} \mathrm{H}_{158} \mathrm{~N}_{27} \mathrm{O}_{30} \mathrm{~S}_{2}{ }^{3+}[\mathrm{M}+3 \mathrm{H}]^{3+}:$ 856.70, found 856.82; $\mathrm{C}_{124} \mathrm{H}_{159} \mathrm{~N}_{27} \mathrm{O}_{30} \mathrm{~S}_{2}{ }^{4+}[\mathrm{M}+4 \mathrm{H}]^{4+}$ : 642.78, found 642.91 (Supporting Information, Figure S13).

Fluorescence Polarization (FP) Assays. Protein concentrations and DMSO stock concentrations of unlabeled peptides were determined by UV absorbance (NanoDrop One ${ }^{\mathrm{C}}$, ThermoFisher Scientific) at $280 \mathrm{~nm}$. The DMSO stock of TAMRA ligand (9) was determined by weight of the corresponding TFA salt $(\mathrm{MW}+5 \times \mathrm{TFA}=$ $3138 \mathrm{~g} / \mathrm{mol}$ ). Binding affinities were determined in a 384-well plate format (Corning Life Science) using a Safire 2 plate reader (Tecan). The instrument $G$-factor was calibrated to give an initial millipolarization at 20 (excitation at $530 \mathrm{~nm}$; emission at $580 \mathrm{~nm}$ ) and the instrumental $Z$-factor was adjusted to maximum fluorescence. All measurements were conducted in phosphate-buffered saline (PBS, $\mathrm{pH}$ $=7.4$ ) at $25{ }^{\circ} \mathrm{C}$. In a FP saturation assay, $50 \mathrm{nM}$ of 9 was mixed with increasing concentrations $(0.125-213 \mu \mathrm{M})$ of $\alpha$-Cbtx. The resulting polarization was plotted as a function of the protein concentration and fitted to a one-site binding model GraphPad Prism 7.0 software to yield the $K_{\mathrm{d}}$ at $50 \%$ saturation. The binding experiment was performed as a single experiment with two replicates. FP competition experiments were conducted by mixing a preformed $\alpha$-Cbtx:9 complex at fixed concentration $(40 \mu \mathrm{M} / 50 \mathrm{nM})$ with varying unlabeled peptide concentrations ranging from $0.2-1024 \mu \mathrm{M}$. The polarization (mP) was plotted as a function of peptide concentration and fitted to a sigmoidal dose response curve using GraphPad Prism 7 software. The $K_{\mathrm{i}}$ values were calculated according to the equations by NikolovskaColeska et al. ${ }^{38}$ The $K_{\mathrm{i}}$ values were determined form three individual experiments performed with two replicates.

$$
\begin{aligned}
& \left([P]_{0}\right)^{2}+\left(K_{\mathrm{d}}+[L]_{\mathrm{T}}\right) \times[P]_{0}-[P]_{\mathrm{T}}=0 \\
& {[P L]_{0}=[P]_{\mathrm{T}}-[P]_{0}} \\
& {[L]_{0}=[L]_{\mathrm{T}}-[P L]_{0}} \\
& {[P L]_{50}=[P L]_{0} \times 1 / 2} \\
& {[L]_{50}=[L]_{\mathrm{T}}-[P L]_{50}} \\
& {[I]_{50}=\mathrm{IC}_{50}-[P]_{\mathrm{T}}+K_{\mathrm{d}} \times[P L]_{50} /[L]_{50}+[P L]_{50}} \\
& K_{\mathrm{i}}=[I]_{50} /\left([L]_{50} / K_{\mathrm{d}}+[P]_{0} / K_{\mathrm{d}}+1\right)
\end{aligned}
$$

$P$, protein $(\alpha$-Cbtx); L, ligand (TAMRA-peptide 9); I, inhibitor (peptide 1 or 12); $K_{\mathrm{d}}$, dissociation constant of the protein-ligand complex; $[P]_{\mathrm{T}}$, total protein concentration; $[L]_{\mathrm{T}}$, total ligand concentration; $[P]_{0}$, unbound protein concentration at $0 \%$ inhibition; $[L]_{0}$, unbound ligand concentration at $0 \%$ inhibition; $[P L]_{0}$, proteinligand complex concentration at $0 \%$ inhibition; $[P]_{50}$, unbound protein concentration at $50 \%$ inhibition; $[L]_{50}$, unbound ligand concentration at $50 \%$ inhibition; $[P L]_{50}$, protein-ligand complex concentration at $50 \%$ inhibition; $[I]_{50}$, unbound inhibitor concentration at $50 \%$ inhibition; $\mathrm{IC}_{50}$, half maximal inhibitory concentration; $K_{\mathrm{i}}$, dissociation constant of the protein-inhibitor complex.

Crystallization and Structure Determination. $\alpha$-Cbtx (lyophilized powder, $\geq 99 \%$, Latoxan) and 12 ( $\geq 95 \%$, GenScript) were solubilized in $20 \mathrm{mM}$ HEPES, $\mathrm{pH} 7.2,100 \mathrm{mM} \mathrm{NaCl}$ at concentrations of $14.4 \mathrm{mg} \mathrm{mL}^{-1}(1.87 \mathrm{mM})$ and $8.2 \mathrm{mg} \mathrm{mL}^{-1}(5.5 \mathrm{mM})$, respectively, and mixed at 1:1.2 molar ratio. Crystallization trays were set up with a semiautomated pipetting robot (Gryphon, Art Robbins Instruments). Best crystals grew in $0.1 \mathrm{M}$ carboxylic acids (sodium formate/ ammonium acetate/sodium citrate/sodium potassium tartrate/sodium oxamate), 0.1 M HEPES/MOPS, pH 7.5, 30.0\% v/v PEG 500 MME/ PEG 20000 (Morpheus Crystallization Screen, Molecular Dimensions) and were directly flash frozen in liquid nitrogen. Data sets were collected at beamline MX14.2, BESSY Berlin ${ }^{39}$ and beamline P13, EMBL Hamburg, respectively. Diffraction data was processed with $\mathrm{XDSAPP}^{40,41}$ and initial phases were obtained by molecular replacement using phenix.phaser ${ }^{42}$ with the neurotoxin-1 from Naja naja oxiana (PDB $1 \mathrm{NTN},{ }^{43}$ as a search model. A molecular model for the peptide portion of 12 could be built unambiguously into the remaining difference density. The final model was obtained through iterative cycles of model building in $\mathrm{Coot}^{44}$ and refinement with refmac/phenix.refine $e^{42,45}$ and is deposited at the protein database (PDB 6ZFM).

Quantification and Statistical Analysis. In Phage display screening, sequencing identified only two peptide binders of $\alpha$-Cbtx, and both were characterized further. In Deep sequencing of phage libraries and selection of an additional six peptides for testing, several more potential peptide binders were identified, but only six were selected for further characterization based on their amino acid sequence identity with proven binders from Phage Display Screening.

Data from Electrophysiological assays are mean \pm SEM $(n=2-4$ oocytes in Figure 1B; $n=3$ oocytes in Figure 2A,B; and $n=2-5$ in Supporting Information, Figure S1B, as indicated in figure legends). We have chosen to show SEM error bars for the few groups where $n=2$, as this shows the range of these data. To establish that, e.g., peptide 1 
prevented $\alpha$-Cbtx from inhibiting acetylcholine-gated currents through acetylcholine receptors, we compared the mean current amplitude (relative to control) in the presence of $\alpha$-Cbtx to the mean current amplitude (relative to control) in the presence of both $\alpha$-Cbtx and peptide 1, using a two-tailed unpaired $t$ test (GraphPad Prism).

In FP assays, the binding saturation with 9 and $\alpha$-Cbtx was performed as a single experiment with two replicates. For competition with 1 and 12, $K_{\mathrm{i}}$ values were determined from three individual experiments performed with two replicates. Data are given as mean \pm SEM $K_{\mathrm{i}}$ values were calculated according to Nikolovska-Coleska et al. ${ }^{38}$ and compared using a two-tailed unpaired $t$ test (GraphPad Prism).

\section{ASSOCIATED CONTENT}

\section{SI Supporting Information}

The Supporting Information is available free of charge at https://pubs.acs.org/doi/10.1021/acs.jmedchem.0c01202.

Effects of additional peptides on $\alpha$-cobratoxin inhibition of nAChRs; chemical stability of peptides 1 and 12; architecture of the 12: $\alpha$-Cbtx complex observed in the crystal structure; structurally homologous $\alpha$-neurotoxin binding interactions with other proteins; HPLC chromatograms and MS spectra; PDB file 6ZFM (12: $\alpha$-Cbtx Xray cocrystal structure) (PDF)

\section{Accession Codes}

Coordinates and structure factors for the 12: $\alpha$-Cbtx X-ray cocrystal structure have been deposited in the RCSB Protein Data Bank with accession number PBD 6ZFM. Authors will release the atomic coordinates and experimental data upon article publication.

\section{AUTHOR INFORMATION}

\section{Corresponding Authors}

Timothy Lynagh - Sars International Centre for Marine Molecular Biology, University of Bergen, 5008 Bergen, Norway; Center for Biopharmaceuticals \& Department of Drug Design and Pharmacology, Faculty of Health and Medical Sciences, University of Copenhagen, DK-2100 Copenhagen, Denmark; ๑ orcid.org/0000-0003-4888-4098; Email: tim.lynagh@ uib.no

Brian Lohse - Department of Drug Design and Pharmacology, Faculty of Health and Medical Sciences, University of Copenhagen, DK-2100 Copenhagen, Denmark; Email: bril@ sund.ku.dk

\section{Authors}

Stephan Kiontke - Division of Structural Biology, Department of Biology/Chemistry, University of Osnabrück, Osnabrück 49076, Germany; Faculty of Biology, Department of Plant Physiology and Photobiology, Philipps-Universität Marburg, 35032 Marburg, Germany

Maria Meyhoff-Madsen - Department of Drug Design and Pharmacology, Faculty of Health and Medical Sciences, University of Copenhagen, DK-2100 Copenhagen, Denmark

Bengt H. Gless - Center for Biopharmaceuticals \& Department of Drug Design and Pharmacology, Faculty of Health and Medical Sciences, University of Copenhagen, DK-2100 Copenhagen, Denmark

Jónas Johannesen - Department of Drug Design and Pharmacology, Faculty of Health and Medical Sciences, University of Copenhagen, DK-2100 Copenhagen, Denmark

Sabrina Kattelmann - Institute of Biochemistry, University of Münster, 48149 Münster, Germany
Anders Christiansen - Fluid Array Systems and Technology, Nano and Bio-physical Systems, Department of Health Technology, Technical University of Denmark, DK-2800 Kongens Lyngby, Denmark

Martin Dufva - Fluid Array Systems and Technology, Nano and Bio-physical Systems, Department of Health Technology, Technical University of Denmark, DK-2800 Kongens Lyngby, Denmark

Andreas H. Laustsen - Department of Drug Design and Pharmacology, Faculty of Health and Medical Sciences, University of Copenhagen, DK-2100 Copenhagen, Denmark

Kanchan Devkota - Department of Drug Design and Pharmacology, Faculty of Health and Medical Sciences, University of Copenhagen, DK-2100 Copenhagen, Denmark

Christian A. Olsen - Center for Biopharmaceuticals \& Department of Drug Design and Pharmacology, Faculty of Health and Medical Sciences, University of Copenhagen, DK2100 Copenhagen, Denmark; 이이.org/0000-0002-29538942

Daniel Kümmel - Division of Structural Biology, Department of Biology/Chemistry, University of Osnabrück, Osnabrück 49076, Germany; Institute of Biochemistry, University of Münster, 48149 Münster, Germany

Stephan Alexander Pless - Center for Biopharmaceuticals \& Department of Drug Design and Pharmacology, Faculty of Health and Medical Sciences, University of Copenhagen, DK2100 Copenhagen, Denmark; 이이.org/0000-0001-6654$114 \mathrm{X}$

Complete contact information is available at:

https://pubs.acs.org/10.1021/acs.jmedchem.0c01202

\section{Author Contributions}

B.L. conceived the study; T.L., B.H.G., A.C., M.D., K.D., A.H.L., C.A.O., D.K., S.A.P. and B.L. designed experiments; B.L. and B.H.G. performed peptide synthesis; B.L. and J.J. performed phage display; B.H.G. and M.M.-M. performed fluorescence polarization assays; T.L. performed electrophysiology; A.C. performed deep sequencing; S. Kiontke, S. Kattelmann, and D.K. performed X-ray crystallography; T.L., B.H.G., A.H.L., K.D., D.K., and B.L. analyzed the data. M.D., A.H.L., C.A.O., D.K., S.A.P. and B.L. provided supervision. T.L., D.K., and B.L. wrote the manuscript with input from all other authors.

\section{Notes}

The authors declare the following competing financial interest(s): Brian Lohse is owner of Serpentides and therefore declares a commercial interest in the development of peptidebased antivenoms.

\section{ACKNOWLEDGMENTS}

This work was supported by Carlsberg Foundation grant 2013_01_0333 and Lundbeck Foundation grant R289-20182074 to C.A.O., Lundbeck Foundation Fellowship R139-201212390 to S.A.P., and the Tech Transfer Office, University of Copenhagen (to B.L.). We thank Morten Jørgensen, Brian Bentzen, and Jonas Caspersen, at Terrariet, Vissenbjerg, Denmark, for Naja kaouthia venom used in preliminary exploratory studies.

\section{ABBREVIATIONS USED}

AChBP, acetylcholine binding protein; nAChRs, acetylcholine receptors; PEG, polyethelene glycol; TAMRA, 5(6)-carboxyte- 
tramethylrhodamine; $\alpha$-Bgtx, $\alpha$ bungarotoxin; $\alpha$-Cbtx, $\alpha$ cobratoxin

\section{REFERENCES}

(1) Gutiérrez, J. M.; Calvete, J. J.; Habib, A. G.; Harrison, R. A.; Williams, D. J.; Warrell, D. A. Snakebite envenoming. Nat. Rev. Dis. Primers 2017, 3, 17063.

(2) Mohapatra, B.; Warrell, D. A.; Suraweera, W.; Bhatia, P.; Dhingra, N.; Jotkar, R. M.; Rodriguez, P. S.; Mishra, K.; Whitaker, R.; Jha, P. Million Death Study, C., Snakebite mortality in India: a nationally representative mortality survey. PLoS Neglected Trop. Dis. 2011, 5 (4), No. e1018.

(3) Bolon, I.; Finat, M.; Herrera, M.; Nickerson, A.; Grace, D.; Schütte, S.; Babo Martins, S.; Ruiz de Castañeda, R. Snakebite in domestic animals: first global scoping review. Preventive Veterinary Medicine 2019, 170, 104729.

(4) de Silva, H. A.; Ryan, N. M.; de Silva, H. J. Adverse reactions to snake antivenom, and their prevention and treatment. Br. J. Clin. Pharmacol. 2016, 81 (3), 446-452.

(5) León, G.; Vargas, M.; Segura, Á.; Herrera, M.; Villalta, M.; Sánchez, A.; Solano, G.; Gómez, A.; Sánchez, M.; Estrada, R.; Gutiérrez, J. M. Current technology for the industrial manufacture of snake antivenoms. Toxicon 2018, 151, 63-73.

(6) Snake bite-the neglected tropical disease. Lancet, 2015, 386 (9999) 1110.

(7) Laustsen, A. H.; Engmark, M.; Milbo, C.; Johannesen, J.; Lomonte, B.; Gutiérrez, J. M.; Lohse, B. From fangs to pharmacology: The future of snakebite envenoming therapy. Curr. Pharm. Des. 2016, 22 (34), 5270-5293.

(8) Williams, H. F.; Layfield, H. J.; Vallance, T.; Patel, K.; Bicknell, A. B.; Trim, S. A.; Vaiyapuri, S. The urgent need to develop novel strategies for the diagnosis and treatment of snakebites. Toxins 2019, 11 (6), 363.

(9) Modahl, C. M.; Mukherjee, A. K.; Mackessy, S. P. An analysis of venom ontogeny and prey-specific toxicity in the Monocled Cobra (Naja kaouthia). Toxicon 2016, 119, 8-20.

(10) Suryamohan, K.; Krishnankutty, S. P.; Guillory, J.; Jevit, M.; Schröder, M. S.; Wu, M.; Kuriakose, B.; Mathew, O. K.; Perumal, R. C.; Koludarov, I.; Goldstein, L. D.; Senger, K.; Dixon, M. D.; Velayutham, D.; Vargas, D.; Chaudhuri, S.; Muraleedharan, M.; Goel, R.; Chen, Y.-J. J.; Ratan, A.; Liu, P.; Faherty, B.; de la Rosa, G.; Shibata, H.; Baca, M.; Sagolla, M.; Ziai, J.; Wright, G. A.; Vucic, D.; Mohan, S.; Antony, A.; Stinson, J.; Kirkpatrick, D. S.; Hannoush, R. N.; Durinck, S.; Modrusan, Z.; Stawiski, E. W.; Wiley, K.; Raudsepp, T.; Kini, R. M.; Zachariah, A.; Seshagiri, S. The Indian cobra reference genome and transcriptome enables comprehensive identification of venom toxins. Nat. Genet. 2020, 52 (1), 106-117.

(11) Wong, K. Y.; Tan, C. H.; Tan, N. H. Venom and purified toxins of the spectacled cobra (Naja naja) from Pakistan: insights into toxicity and antivenom neutralization. Am. J. Trop. Med. Hyg. 2016, 94 (6), $1392-1399$.

(12) Barber, C. M.; Isbister, G. K.; Hodgson, W. C. Alpha neurotoxins. Toxicon 2013, 66, 47-58.

(13) Gutiérrez, J. M.; Solano, G.; Pla, D.; Herrera, M.; Segura, Á.; Villalta, M.; Vargas, M.; Sanz, L.; Lomonte, B.; Calvete, J. J.; León, G. Assessing the preclinical efficacy of antivenoms: from the lethality neutralization assay to antivenomics. Toxicon 2013, 69, 168-179.

(14) Richard, G.; Meyers, A. J.; McLean, M. D.; Arbabi-Ghahroudi, M.; MacKenzie, R.; Hall, J. C. In vivo neutralization of $\alpha$-cobratoxin with high-affinity llama single-domain antibodies (VHHs) and a VHHFc antibody. PLoS One 2013, 8 (7), No. e69495.

(15) Kulkeaw, K.; Sakolvaree, Y.; Srimanote, P.; Tongtawe, P.; Maneewatch, S.; Sookrung, N.; Tungtrongchitr, A.; Tapchaisri, P.; Kurazono, H.; Chaicumpa, W. Human monoclonal ScFv neutralize lethal Thai cobra, Naja kaouthia, neurotoxin. J. Proteomics 2009, 72 (2), 270-282.

(16) Laustsen, A. H.; Karatt-Vellatt, A.; Masters, E. W.; Arias, A. S.; Pus, U.; Knudsen, C.; Oscoz, S.; Slavny, P.; Griffiths, D. T.; Luther, A. M.; Leah, R. A.; Lindholm, M.; Lomonte, B.; Gutiérrez, J. M.;
McCafferty, J. In vivo neutralization of dendrotoxin-mediated neurotoxicity of black mamba venom by oligoclonal human IgG antibodies. Nat. Commun. 2018, 9, 3928.

(17) Krissinel, E.; Henrick, K. Inference of macromolecular assemblies from crystalline state. J. Mol. Biol. 2007, 372 (3), 774-797.

(18) Nirthanan, S.; Gwee, M. C. E. Three-finger alpha-neurotoxins and the nicotinic acetylcholine receptor, forty years on. J. Pharmacol. Sci. 2004, 94 (1), 1-17.

(19) Rahman, M. M.; Teng, J.; Worrell, B. T.; Noviello, C. M.; Lee, M.; Karlin, A.; Stowell, M. H. B.; Hibbs, R. E. Structure of the native muscle-type nicotinic receptor and inhibition by snake venom toxins. Neuron 2020, 106 (6), 952-962.

(20) Bourne, Y.; Talley, T. T.; Hansen, S. B.; Taylor, P.; Marchot, P. Crystal structure of a Cbtx-AChBP complex reveals essential interactions between snake alpha-neurotoxins and nicotinic receptors. EMBO J. 2005, 24 (8), 1512-1522.

(21) Jurgilas, P. B.; Neves-Ferreira, A. G.; Domont, G. B.; Perales, J. PO41, a snake venom metalloproteinase inhibitor isolated from Philander opossum serum. Toxicon 2003, 42 (6), 621-628.

(22) Karain, B. D.; Lee, M. K. H.; Hayes, W. K. C60 fullerenes as a novel treatment for poisoning and envenomation: a proof-of-concept study for snakebite. J. Nanosci. Nanotechnol. 2016, 16 (7), 7764-7771.

(23) Lewin, M.; Samuel, S.; Merkel, J.; Bickler, P. Varespladib (LY315920) appears to be a potent, broad-spectrum, inhibitor of snake venom phospholipase A2 and a possible pre-referral treatment for envenomation. Toxins 2016, 8 (9), 248.

(24) Scherf, T.; Kasher, R.; Balass, M.; Fridkin, M.; Fuchs, S.; Katchalski-Katzir, E. A $\beta$-hairpin structure in a 13 -mer peptide that binds $\alpha$-bungarotoxin with high affinity and neutralizes its toxicity. Proc. Natl. Acad. Sci. U. S. A. 2001, 98 (12), 6629-6634.

(25) Fosgerau, K.; Hoffmann, T. Peptide therapeutics: current status and future directions. Drug Discovery Today 2015, 20 (1), 122-128.

(26) Harel, M.; Kasher, R.; Nicolas, A.; Guss, J. M.; Balass, M.; Fridkin, M.; Smit, A. B.; Brejc, K.; Sixma, T. K.; Katchalski-Katzir, E.; Sussman, J. L.; Fuchs, S. The binding site of acetylcholine receptor as visualized in the X-ray structure of a complex between $\alpha$-bungarotoxin and a mimotope peptide. Neuron 2001, 32 (2), 265-275.

(27) Chandy, K. G.; Norton, R. S. Peptide blockers of Kv1.3 channels in $\mathrm{T}$ cells as therapeutics for autoimmune disease. Curr. Opin. Chem. Biol. 2017, 38, 97-107.

(28) Guidotti, G.; Brambilla, L.; Rossi, D. Cell-penetrating peptides: from basic research to clinics. Trends Pharmacol. Sci. 2017, 38 (4), $406-$ 424.

(29) Strohl, W. R. Fusion proteins for half-life extension of biologics as a strategy to make biobetters. BioDrugs 2015, 29, 215-239.

(30) Di, L. Strategic approaches to optimizing peptide ADME properties. AAPS J. 2015, 17 (1), 134-143.

(31) Kalafatovic, D.; Giralt, E. Cell-penetrating peptides: design strategies beyond primary structure and amphipathicity. Molecules 2017, 22 (11), 1929.

(32) Longbottom, J.; Shearer, F. M.; Devine, M.; Alcoba, G.; Chappuis, F.; Weiss, D. J.; Ray, S. E.; Ray, N.; Warrell, D. A.; Ruiz de Castañeda, R.; Williams, D. J.; Hay, S. I.; Pigott, D. M. Vulnerability to snakebite envenoming: a global mapping of hotspots. Lancet 2018, 392 (10148), 673-684.

(33) Lohse, B. Synthetic antivenoms for snakebites: a slithering road! Biochemist 2019, 41 (6), 6-9.

(34) Lynagh, T.; Komnatnyy, V. V.; Pless, S. A. Unique contributions of an arginine side chain to ligand recognition in a glutamate-gated chloride channel. J. Biol. Chem. 2017, 292 (9), 3940-3946.

(35) Revah, F.; Bertrand, D.; Galzi, J. L.; Devillers-Thiéry, A.; Mulle, C.; Hussy, N.; Bertrand, S.; Ballivet, M.; Changeux, J. P. Mutations in the channel domain alter desensitization of a neuronal nicotinic receptor. Nature 1991, 353 (6347), 846-849.

(36) Halevi, S.; Yassin, L.; Eshel, M.; Sala, F.; Sala, S.; Criado, M.; Treinin, M. Conservation within the RIC-3 Gene Family: effectors of mammalian nicotinic acetylcholine receptor expression. J. Biol. Chem. 2003, 278 (36), 34411-34417. 
(37) Dahan, D. S.; Dibas, M. I.; Petersson, E. J.; Auyeung, V. C.; Chanda, B.; Bezanilla, F.; Dougherty, D. A.; Lester, H. A. A fluorophore attached to nicotinic acetylcholine receptor $\beta \mathrm{M} 2$ detects productive binding of agonist to the $\alpha \delta$ site. Proc. Natl. Acad. Sci. U. S. A. 2004, 101 (27), 10195-10200.

(38) Nikolovska-Coleska, Z.; Wang, R.; Fang, X.; Pan, H.; Tomita, Y.; Li, P.; Roller, P. P.; Krajewski, K.; Saito, N. G.; Stuckey, J. A.; Wang, S. Development and optimization of a binding assay for the XIAP BIR3 domain using fluorescence polarization. Anal. Biochem. 2004, 332 (2), 261-273.

(39) Mueller, U.; Darowski, N.; Fuchs, M. R.; Forster, R.; Hellmig, M.; Paithankar, K. S.; Puhringer, S.; Steffien, M.; Zocher, G.; Weiss, M. S. Facilities for macromolecular crystallography at the HelmholtzZentrum Berlin. J. Synchrotron Radiat. 2012, 19 (3), 442-449.

(40) Kabsch, W. XDS. Acta Crystallogr., Sect. D: Biol. Crystallogr. 2010, 66 (2), 125-132.

(41) Krug, M.; Weiss, M. S.; Heinemann, U.; Mueller, U. XDSAPP: a graphical user interface for the convenient processing of diffraction data using XDS. J. Appl. Crystallogr. 2012, 45 (3), 568-572.

(42) Adams, P. D.; Afonine, P. V.; Bunkoczi, G.; Chen, V. B.; Davis, I. W.; Echols, N.; Headd, J. J.; Hung, L.-W.; Kapral, G. J.; GrosseKunstleve, R. W.; McCoy, A. J.; Moriarty, N. W.; Oeffner, R.; Read, R. J.; Richardson, D. C.; Richardson, J. S.; Terwilliger, T. C.; Zwart, P. H. PHENIX: a comprehensive Python-based system for macromolecular structure solution. Acta Crystallogr., Sect. D: Biol. Crystallogr. 2010, 66 (2), 213-221.

(43) Nickitenko, A. V.; Michailov, A. M.; Betzel, C.; Wilson, K. S. Three-dimensional structure of neurotoxin-1 from Naja naja oxiana venom at 1.9 Å resolution. FEBS Lett. 1993, 320 (2), 111-117.

(44) Emsley, P.; Cowtan, K. Coot: model-building tools for molecular graphics. Acta Crystallogr., Sect. D: Biol. Crystallogr. 2004, 60 (12 Part 1), 2126-2132.

(45) Murshudov, G. N.; Vagin, A. A.; Dodson, E. J. Refinement of macromolecular structures by the maximum-likelihood method. Acta Crystallogr., Sect. D: Biol. Crystallogr. 1997, 53 (3), 240-255.

\section{NOTE ADDED AFTER ASAP PUBLICATION}

Supporting Information Figure S2 was misformatted in the version published on November 4, 2020 and was correctly restored on November 5, 2020. 